\title{
Reform and exploration of computer aided design and Analysis Course under the background of "new engineering"
}

\author{
Zhang Enguang ${ }^{1}$, Wang $\mathrm{Li}^{1}$ \\ ${ }^{1}$ School of mechanical engineering, Zhuhai College of Jilin University, Zhuhai, 519041, China
}

\begin{abstract}
In response to the requirements of new engineering construction and reform, the new experimental teaching mode of the comprehensive practice link of computer-aided engineering analysis course was explored, and the "finite element analysis of the lateral stabilizer bar of new energy bus" was introduced into the comprehensive practice of the course to train students' autonomy learning ability. At the same time, it has improved students' scientific research and teamwork ability, and used project-based teaching as a link to open up the separation between undergraduate teaching and postgraduate teaching, cultivated students' ability to continue learning, strengthened the combination of theoretical knowledge and engineering application, and improved student in solving the ability of the problem. It provides a reference for the curriculum reform under the background of "new engineering ".
\end{abstract}

\section{Introduction}

In 2017, the Department of higher education of the Ministry of Education issued the notice on the development of new engineering research and practice, which requires deepening the reform of engineering education, cultivating engineering and technical talents facing the new industrial system, and assisting the economic transformation and upgrading construction with new technologies, new formats, new models and new industries, and the development of new engineering courses has become the practical needs of social and economic development "It is not only to create a new major, nor to write a thesis, but also to break through the five bottlenecks, that is, to break through the barriers of discipline, to cross the barriers of specialty, to break through the gap between the University and the enterprise, and to arouse the indifference of teachers and students[1]. Many experts and scholars have expounded, interpreted and practiced the "new" and connotation of new engineering[2], and reached a certain consensus in the construction and reform of engineering education.

Computer aided course belongs to the course of technology and method. As a course integrating information science and engineering, computer aided design and analysis is the basis of industrial intelligence, automation and informatization. At present, many colleges and universities have set up the course of "computer aided design and analysis", but the teaching content of most courses is too old and outdated, and there is no introduction of advanced technology in the industry; either there are too many theories, which make it difficult for students to master and apply; or the course is "instrumental" and becomes the explanation of software use. Computer aided design and analysis courses are also the teaching characteristics of our school of mechanical engineering, especially under the background that Siemens presented genuine NX software and NASTRAN software through the "GO PLM" program. Nx CAD / CAE / CAM and other courses have been set up in our school, which are connected with other related courses in the training program, so that students can learn computeraided and analysis courses systematically. However, with the development of new engineering, many cases in the course are slightly out of date and cannot cultivate students' comprehensive ability. Therefore, in view of the construction goal of "new engineering", it is urgent to reform the contents, teaching methods and teaching modes of computer aided design and analysis courses.

The course of computer-aided engineering analysis in our school is set up with comprehensive practice, which is oriented to mechanical design and manufacturing, automation and mechanical and electronic engineering. The course is offered in the first semester of junior year.The students have already studied the course of computer aided design. In view of CAD / CAE, mechanical design, material mechanics, engineering materials and other related teaching contents, on the basis of learning the traditional knowledge points in the classroom, the scientific research project "finite element analysis of lateral stabilizer bar of new energy bus" is simplified and introduced into the project-based teaching of comprehensive practice of computer-aided engineering analysis course, so that students can understand the key components of new energy bus, and the parametric design, 
assembly and finite element analysis of lateral stabilizer bar of new energy vehicle are carried out by using manufacturing information software $\mathrm{nx8.0}$. The integration of computer-aided technology and traditional mechanical design and analysis is realized. The students' literature retrieval and reading ability are trained. At the same time, the scientific research literacy and team cooperation ability of the students are improved. The project-based teaching is used as the link to break through the separation of this research It has trained the students' ability to continue learning and realized the concept of new engineering training.

\section{Design of comprehensive practice}

Students study computer-aided engineering analysis in the fifth semester. Although the students have studied mechanical design, material mechanics, computer-aided design and other courses before, we can find that students are vague about the concepts of mechanical analysis, stress distribution of parts, stiffness and other concepts in the 4th semester of reducer design course, and can not well understand the more abstract concepts such as stress deformation of parts. Through the division of labor among different members of the project team, the students first searched and read the literature on the role and research status of the "automobile stabilizer bar", and then used NX software to establish the parametric model of the stabilizer bar and assemble it. Then, they looked up the common materials and different boundary conditions of the stabilizer bar and its bushing The rationality of the analysis is discussed. Students who have spare force can also continue to study the optimization of hollow stabilizer bar. The specific process is shown in Figure 1

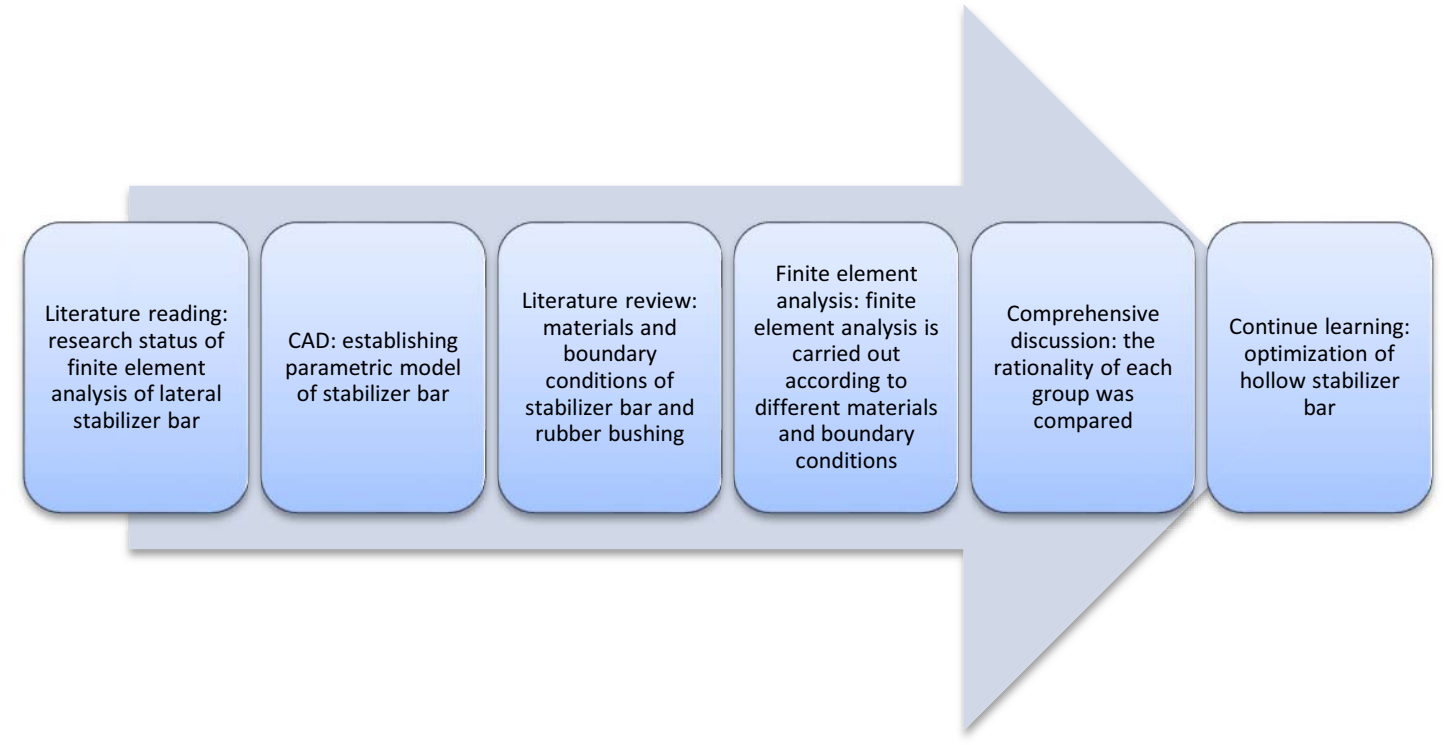

Figure 1 process of comprehensive practice

\section{Function of stabilizer bar}

Stabilizer bar is an auxiliary elastic element in automobile suspension. As shown in Figure 2, in order to improve the ride comfort of the vehicle, the suspension stiffness is usually designed to be relatively low, and the result is that the driving stability of the vehicle is affected. Therefore, the lateral stabilizer bar structure is adopted in the suspension system to improve the stiffness of the suspension roll angle and reduce the body inclination. The stabilizer bar is mainly used to prevent the car body from excessive lateral tilt when turning, so as to keep the car as balanced as possible. The stabilizer bar can be regarded as a torsion spring to stabilize and prevent rollover.

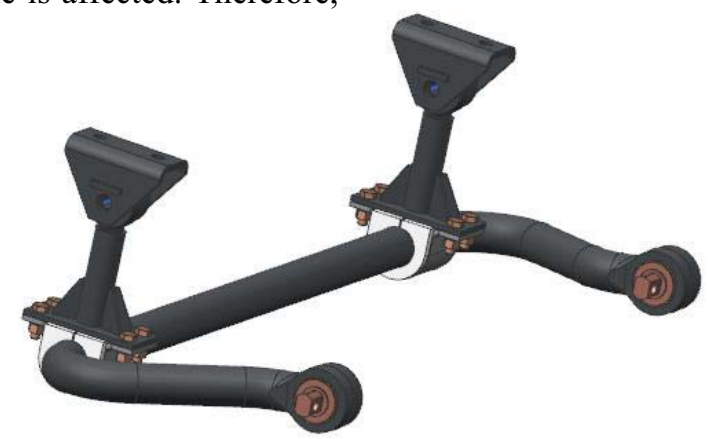

Fig. 2 assembly structure of stabilizer bar

The probability of rollover of vehicles without stabilizer bar is much higher, especially in the case of high mass, high centroid and changeable road conditions. The stabilizer bar of new energy bus is an important part to prevent rollover. In recent years, many automobile companies pay attention to the research of stabilizer bar. 


\section{Research status of stabilizer bar at home and abroad}

Japan Spring Company (NHK) has established a Nisheng spring company in China. The main products are suspension spring and stabilizer bar. Researchers from NHK company regard the stiffness of stabilizer bar as linear and continuous, analyze its stress and outer diameter growth rate, mass reduction rate and wall thickness rate, and design and produce hollow stabilizer bar by cold forming bending radius design method and high frequency electromagnetic induction welding technology [3].

M. sampon et al. [4,5] of Cambridge University applied the active stabilizer bar control technology to the high center of gravity multi node articulated vehicle model, and established a linear anti rollover model, and its effectiveness was verified by simulation test.

Hangzhou Institute of technology and Shanghai Automotive Group put forward the physical model of stabilizer bar support, analyzed the influence of different performance parameters of rubber bushing commonly used in suspension on the handling and comfort performance of suspension. According to the relative movement of stabilizer bar and rubber bushing, the current stabilizer bar is classified as [6]: free rotation, semi free

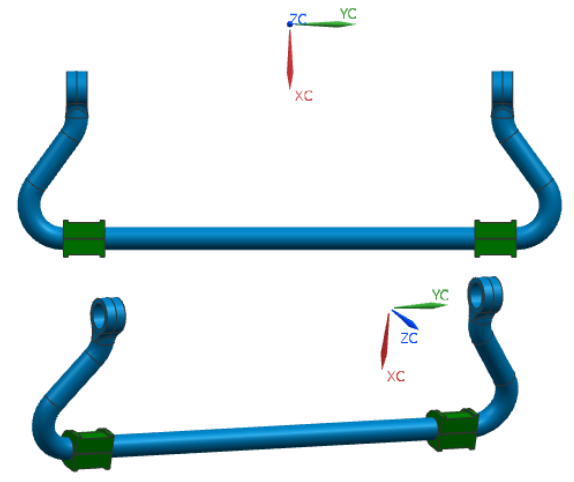

Figure 3 three dimensional model of stabilizer bar

\subsection{Material selection and mesh generation}

The commonly used materials of stabilizer bar are $60 \mathrm{si} 2 \mathrm{cr}$ a, 60si2cr VA, 60Si2MnA, 50CrVA and 55cr3. In this paper, $55 \mathrm{cr} 3$ is selected, with young's modulus of $206 \mathrm{gpa}$, Poisson's ratio of 0.29 , density of $7850 \mathrm{~kg} / \mathrm{m} 3$, ultimate tensile strength of $1225 \mathrm{mpa}$ and yield limit of $1080 \mathrm{mpa}$. When doing the finite element analysis, students are divided into groups and choose different materials. For example, the simulation results of $0 \mathrm{si} 2 \mathrm{cra}, 60 \mathrm{si} 2 \mathrm{cr} \mathrm{VA}$ and $55 \mathrm{cr} 3$ are compared.

The bushing material of stabilizer bar is mostly natural rubber or synthetic rubber, which plays the role of vibration reduction, buffering and noise reduction.

In the automobile chassis parts with rubber bushing, the rubber material is mostly solid rubber, which can be regarded as incompressible material. Rubber material is a common elastomer, which has significant nonlinear characteristics and can withstand maximum strain.

In the finite element analysis of NX, the mesh of solid rotation, tight fit, surface fit and vulcanization 。

Wang Guoli of Jilin University has carried out fatigue simulation analysis and structural optimization on the connecting rod bracket of automobile suspension stabilizer. The cross-section of the bracket is changed from the original constant cross-section to the variable crosssection, which can reduce the fatigue damage and prolong the service life of components [15].

\section{Establishment of finite element model}

\subsection{Parametric design of stabilizer bar}

Nx8.0 was used to establish the parametric model. The modeling, assembly and finite element analysis of this case are completed in $n \times 8.0$, which ensures the unity of data and improves the editability of the model. Nx8.0 supports parametric design and can add user-defined expressions to key variables. For example, the "pipe" command is used to establish the stabilizer bar. The initial inner diameter is 0 and the outer diameter is 25 . The inner diameter expression can be used as the design variable in the future dimension optimization. The parametric design of the stabilizer bar is shown in Figure 3, which is a Ushaped rod with circular cross-section.

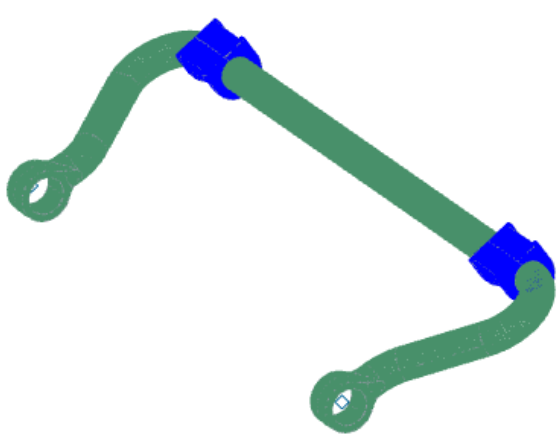

Fig. 4 grid generation

is divided into $3 \mathrm{D}$ tetrahedron and $3 \mathrm{D}$ sweep mesh, and the $3 \mathrm{D}$ tetrahedron is divided into 10 nodes and 4 nodes. In order to save time in classroom teaching, 4-node 3D tetrahedral mesh is used to discretize the stabilizer bar and two bushings, with about 760000 elements and 150000 nodes. The grid after division is shown in Figure 4.

\section{Adding load and constraint and solution analysis}

\subsection{Add load and constraint}

In the simulation, it is difficult to do the finite element analysis of the rubber bushing and the stabilizer bar together. However, if the rubber bushing is ignored, only the y-direction rotational freedom is released at the center of the assembly position of the rubber bushing and the stabilizer bar, so that the error of the stabilizer bar is often large. Secondly, rubber material has nonlinear mechanical properties. If it is replaced by other hard materials, it can not meet the requirements. Therefore, mesh adhesion is 
added between the finite element model of rubber bushing and the finite element model of stabilizer bar in this case.

A grid point is established at the center of the circular hole at both ends of the stabilizer bar, and the grid point is connected with the point surface connection of the circular hole. The forced displacement constraint is added at the central grid point, $30 \mathrm{~mm}$ up and down. As shown in
Figure 5. Do the same in the center of the bushing. Add grid points and establish the point surface connection between the grid points and the outer surface of the bushing. Add user-defined constraints at the grid points, and only retain the rotational degrees of freedom in the $Y$ direction, as shown in Figure 6.

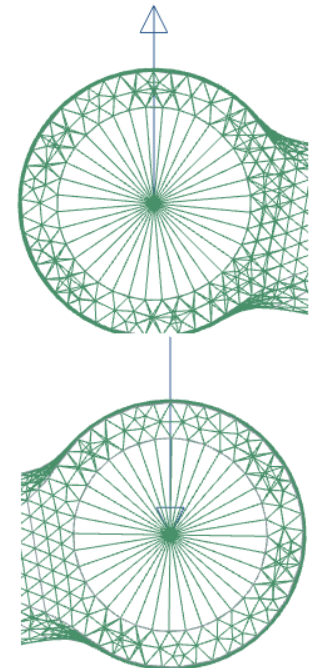

Figure 5 forced displacement load on rubber bushing

Due to the nonlinear mechanical characteristics of rubber bushing, nlstatic 106 of NX NASTRAN solver is selected as the solution type of finite element analysis in this case. The finite element model has 840000 degrees of freedom, and the calculation time is about 15 minutes.

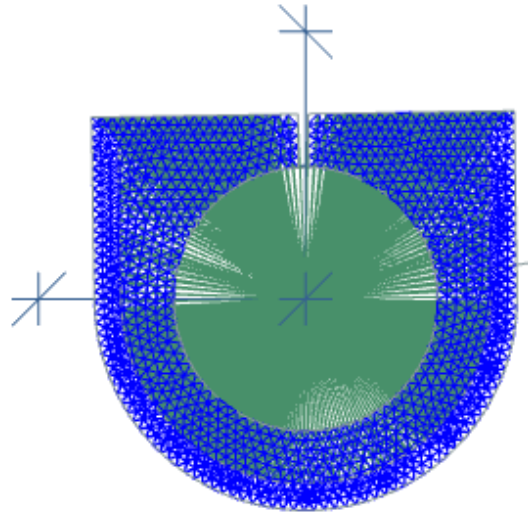

Figure 6 user defined constraints

As shown in Figures 7 and 8, the maximum stress of the stabilizer bar is $708.4 \mathrm{mpa}$ at the node 22395 . The maximum displacement is $34.4 \mathrm{~mm}$ at 102223 . Meet the requirements of safety factor.

\section{2 structural strength and stiffness analysis}

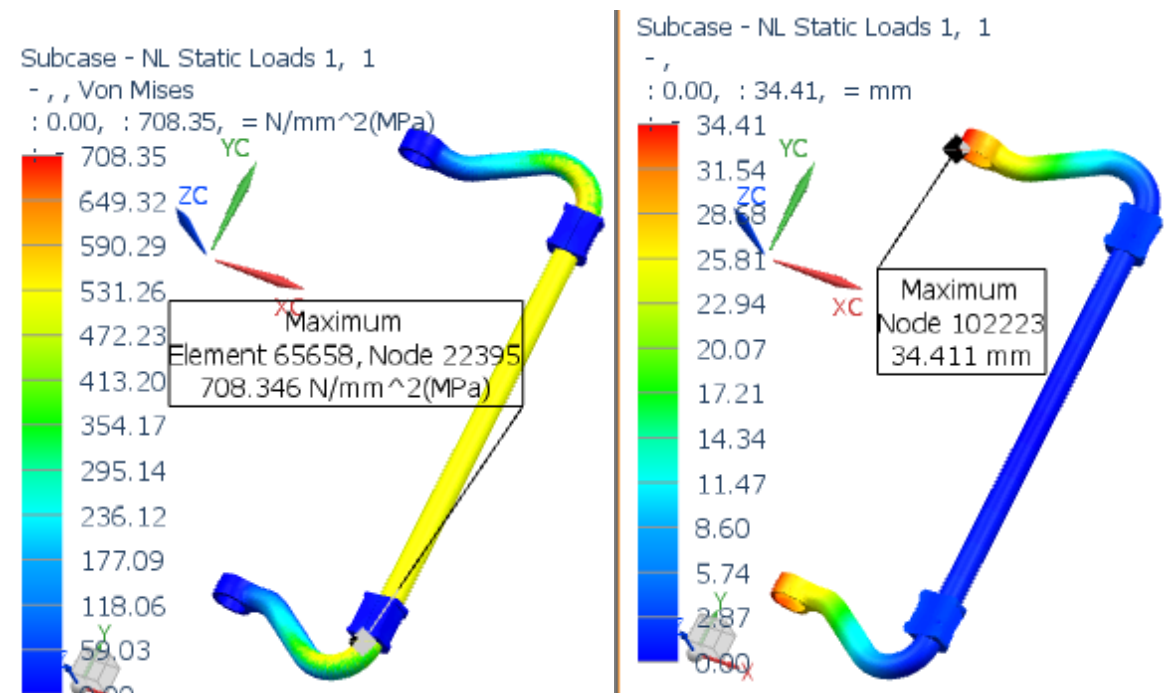

Figure 7 maximum stress of stabilizer bar

Figure 8 maximum deformation of stabilizer bar

University and SAIC Group adopted new high strength

\subsection{Discussion on Structure Optimization of stabilizer bar}

At present, the optimization of stabilizer bars at home and abroad is mostly hollow design, such as mubea and ThyssenKrupp in Germany, NHK in Japan and Silesian University of technology in Poland. Shanghai Jiaotong steel materials to hollow the front and rear stabilizer bars of Rongwei $750 \mathrm{cv}$, and achieved good results

Structural optimization is generally divided into size optimization, shape optimization and topology optimization. Hollow design of stabilizer bar belongs to size optimization. In NX software, the value of expression can be used as variable and stress and strain as constraint 
to achieve the optimization requirement of weight minimization.

At the end of the whole comprehensive practice, the concept of structural optimization and the use of structural optimization commands in CAE module are introduced to students, so that students who have spare power can continue to learn.

\section{7 conclusion}

Aiming at the construction goal of "new engineering", on the basis of learning the traditional knowledge points in the classroom, the scientific research project "finite element analysis of lateral stabilizer bar of new energy bus" is introduced into the comprehensive practice of computer-aided engineering analysis course. In the way of project teaching, students can understand the key components of new energy bus and use manufacturing information software nx8.0 to do parametric design, assembly and finite element analysis of lateral stabilizer bar of new energy vehicles. This realizes the integration of computer-aided technology and traditional mechanical design and analysis, trains students' autonomous learning ability, and improves their scientific research literacy and team cooperation ability. Taking project teaching as the link, breaking through the separation of undergraduate and postgraduate, cultivating students' ability to continue learning and realizing the concept of new engineering training. Through the finite element analysis of the lateral stabilizer bar, the operation ability of students is trained, the abstract knowledge points in the course are embodied, the combination of theoretical knowledge and engineering application is strengthened, and the ability of students to solve problems is improved, which has some reference value for the reform of related courses.

\section{Acknowledgement}

The authors acknowledge the financial supports from teaching quality engineering project " Reform and exploration of computer aided design and Analysis Course under new engineering” (ZLGC20180816、2018010) of Zhuhai College of Jilin University of China.

\section{References}

1. ZHU Zhengwei, ZHOU Hongfang, LI Maoguo. The"New Engineering"Targeting the New Industr ial System [J]. Chongqing Higher Education Res earch,2017,5(03):15-21.

2. Zhong Denghua. Connotations and Actions for Establishing the Emerging Engineering Educatio $\mathrm{n}[\mathrm{J}]$. Research in Higher Education of Engineer ing,2017(03):1-6.

3. Zhao Y,Lee C,Wayne E,et al.Light Truck Stabili zer Bar Attachment Non-linearFatigue Analysis [J].SAE Technical Paper,1998

4. John D, Sampson M. Active Roll Control of Ar ticulated Heavy Vehicles [J]. Vehicle System D ynamics, 2000, 26(5):17-43.
5. Sampson M, Jeppesen B P, Cebon D. The Dev elopment of an Active Roll Control System for Heavy Vehicles [J]. Acs Medicinal Chemistry L etters, 2000, 3(11):897-902.

6. SHAN Hong-yan, YAO bin. Studying of rubber bushings in anti-roll bar system of passenger c ar [J]. Machinery Design \& Manufacture, 2011, (11): 95-97

7. WANG Guo-lil, HUANG Xiao-hai, LIU Shu-hui, LI Qin-wei. Fatigue simulation and structure o ptimization of suspension stabilizer link bracket [J]. Chinese Journal of Engineering Design, 201 3,20 (1):18-21 